\title{
Review of Cucurbita pepo (Pumpkin) its Phytochemistry and Pharmacology
}

\section{Rosa Martha Perez Gutierrez*}

Laboratorio de Investigación de Productos Naturales, Escuela Superior de Ingenieria Quimica e Industrias extractivas IPN. Av. Instituto Politécnico Nacional S/N, Unidad Profesional Adolfo Lopez Mateos cp 07708, Mexico

\begin{abstract}
Cucurbita pepo, is widely used like food and in folk medicine around of the world. This aims a comprehensive of the pharmacological, chemical constituents, and clinical uses. Also have been identified the medicinally important phyto-constituents belonging mainly to cucurbitosides, multiflorane-type triterpenoids, carotenoids, ent-kauranetype diterpene, and cucurbitaglycosides. Extracts and metabolites of this plant, particularly those from seeds and fruits possess useful pharmacological activities. A survey of the literature shows $C$. pepo, is mainly known for its improvement in prostatic hiperplasia (BPH), urinary dysfunction and cytotoxic properties, also has also been used extensively as a hypoglycaemic agent. Many pharmacological studies have demonstrated hepatoprotection, inhibit benign prostatic hiperplasia, antioxidant, anticancer, antimicrobial, antiinflamatory, antidiabetic, and antiulcer activities supporting its traditional uses.
\end{abstract}

Keywords: Antioxidant; Anticancer; Antimicrobial; Antiinflamatory; Cucurbita pepo; Curcurbiteae family

\section{Introduction}

The Curcurbiteae family, also referred as cucurbits form a very large group with approximately 130 genera and 800 species and can be cultivated in warmer region of worldwide and make popular food crop plants some of these species include squashes, pumpkins, melons and gourds. Cucurbita pepo is one of the oldest known cultivated species, with Mexican archaeological evidence from 7000 BC. Thus, it was widely cultivated by indigenous peoples throughout Mexico, Central, and North America before the arrival of Europeans. This plant is native of Northem Mexico and southwestern and eastern USA [1]. These family have medicinal and nutritional benefits. The immature fruits are consumed as a vegetable. The mature fruit is sweet and used to make confectionery, beverages are roasted, or cooked and can be incorporated into baked goods. The seeds, rich in oil, also are used in Mexico, with honey to prepare desserts known as palanquetas. Flower buds and flowers are also edible in Mexico to prepare quesadillas. Some fruit varieties are used with decorative purposes in Halloween party.

\section{Uses in Traditional Medicine}

Ethnopharmacological studies show that Cucurbita pepo is used in many countries for treating numerous diseases, e.g., as an antiinflammatory, antiviral, analgesic urinary disorders, anti-ulcer, antidiabetic and antioxidant $[1,2]$. Traditional medicine, particularly Ayurvedic systems [3], and Chinese [4] have used different parts of the plant including flesh of the fruits and seeds [5] (Table 1). Reporting that pumpkin exhibiting important physiological properties as wound healing, tumour growth inhibition, hypoglycaemic effects and immunomodulating [4]. The seeds are used as a vermifuge, treat problems of the urinary system, hypertension, prevents the formation of kidney stones, alleviate prostate disesases, and enhanced the erysipelas skin infection [6-14].

\section{Phytochemistry}

\section{Fruits}

These are characterized by a low content of fat (2.3\%, pumpkin pulp is not a rich source of oil), carbohydrates (66\%), proteins (3\%) [14], and by a high-carotenoids content with values of 171.9 to 461.9 $\mu \mathrm{g} . \mathrm{g}^{-1}$ [15]. Food value per $100 \mathrm{~g}$ is: Calories $80 \mathrm{kcal}$, crude fibre $11.46 \%$, ash $16 \%$. The mineral analysis indicated that pumpkin pulp contained high levels of $\mathrm{Mn}(0.5 \mathrm{mg} / \mathrm{kg}), \mathrm{Fe}(1.37 \mathrm{mg} / \mathrm{kg}), \mathrm{Cu}(3.9 \mathrm{mg} / \mathrm{kg}), \mathrm{Pb}$ (0.29 mg/kg), P (11.38 mg/kg), Ni (0.5 mg/kg), Ca (179 mg/kg), Mg $(190 \mathrm{mg} / \mathrm{kg}), \mathrm{Na}(159 \mathrm{mg} / \mathrm{kg})$ and $\mathrm{K}(160 \mathrm{mg} / \mathrm{kg})$ [16]. The level of $\mathrm{Pb}$ $(0.21-0.25 \mathrm{mg} / \mathrm{kg})$, and $\mathrm{Cu}(2-5 \mathrm{mg} / \mathrm{kg})$ are within the aceptable range to FAO [17].

\section{Seeds}

Seeds of pumpkin are consumed either roasted or raw and used in cooking and baking as an ingredient of cereals, bread, cakes and salads. Pumpkin seed oil is accepted as edible oil and as a nutraceutical. Pumpkin seed and seed oil are a rich natural source of phytosterols [18], proteins, polyunsaturated fatty acids [19], antioxidant vitamins, carotenoids and tocopherols [20] and various elements [21] due to these components are attributed providing many health benefits.

Seeds contain oil with the main fatty acid components being palmitic (C 16:0, 10.68\%), palmitoleic (C 16: 1, 0.58\%), stearic (C 18:0, 8.67\%) Oleic (C 18: 1, 38.42\%) Linoleic (C 18:2, 39.84\%), Linolenic (C18: 3, 0.68\%), Gadoleic (C20: 1, 1.14\%), total saturated fatty acids (19.35\%), and total unsaturated fatty acids (80.65\%) [1]. Also contain various components such as $p$-aminobenzoic acid, $\gamma$-aminobutic acid, polysaccharides, peptides, proteins, carotenoids as lutein, lutein epoxide, 15-cis-lutein (central-cis)-lutein, 9(9')-cis-lutein, 13(13')-cislutein, $\alpha$-carotene, $\beta$-carotene violaxanthin, auroxanthin epimers, flavoxanthin, luteoxanthin, chrysanthemaxanthin, $\alpha$-cryptoxanthin, $\beta$-cryptoxanthin [22].

Also have been isolated from the seeds sterols which the most abundan was $\Delta^{7.22 .25}$-stigmastatrienol with values of 18.8 to $35.1 \mathrm{~g} / 100$ $\mathrm{g}$ of the total sterol content, following by the $\Delta^{7}$ sterol spinasterol with values of $18.2-23.3 \mathrm{~g} / 100 \mathrm{~g}$ of the total sterol content. $\beta$-sitosterol

*Corresponding author: Rosa Martha Perez Gutierrez, Laboratorio de Investigación de Productos Naturales, Escuela Superior de Ingenieria Quimica e Industrias extractivas IPN. Av. Instituto Politécnico Nacional S/N, Unidad Profesional Adolfo Lopez Mateos cp 07708, Mexico, E-mail: rmpg@prodigy.net.mx

Received December 28, 2015; Accepted January 10, 2016; Published January 15,2016

Citation: Perez Gutierrez RM (2016) Review of Cucurbita pepo (Pumpkin) its Phytochemistry and Pharmacology. Med chem 6: 012-021. doi:10.4172/21610444.1000316

Copyright: $\odot 2016$ Perez Gutierrez RM. This is an open-access article distributed under the terms of the Creative Commons Attribution License, which permits unrestricted use, distribution, and reproduction in any medium, provided the original author and source are credited. 
Citation: Perez Gutierrez RM (2016) Review of Cucurbita pepo (Pumpkin) its Phytochemistry and Pharmacology. Med chem 6: $012-021$. doi:10.4172/2161-0444.1000316

\begin{tabular}{|c|c|c|c|c|}
\hline Place, Country & Part(s) used & Ethno medical uses & Preparation(s) & References \\
\hline Mongolia & Fruits & Treat cold and alleviate ache & Infusion or decoction & [7] \\
\hline Mexico & Seeds & Treat irritable bladder & Are eaten in the diet & [8] \\
\hline Egypt & Seeds & Prostatic complains & Are eaten in the diet & [8] \\
\hline Europe & Seeds & Micturition caused by the prostate & Are eaten in the diet & [9] \\
\hline China & Seeds & Deworming medicine & Are eaten in the diet & [10] \\
\hline Europe & Seeds & Treatment of urinary and prostate disease & Are eaten in the diet & [11] \\
\hline China & Seeds & Anti-parasitic & Are eaten in the diet & [12] \\
\hline China & Seeds & Beneficial to the spleen and lungs & Are eaten in the diet & [13] \\
\hline $\begin{array}{l}\text { Central and North } \\
\text { America }\end{array}$ & Seeds & Taenicide, diuretic, Gastritis, burns, enteritis and Febrile diseases & $\begin{array}{l}\text { Oil of the pumpkin seeds, in doses of } 6 \\
\text { to } 12 \text { drops, several times a day }\end{array}$ & [14] \\
\hline Centro America & Seeds & Headaches and neuralgia & Compress & [6] \\
\hline Centro America & Leaves & Reduced fever & Infusion or decoction & [14] \\
\hline Southwestern USA & Fruits & Cure fatigue and thirst and purify the blood & Infusion or decoction & [14] \\
\hline Southwestern USA & Leaves & $\begin{array}{l}\text { A treatment for nausea, and a boost to haemoglobin content of the } \\
\text { blood. }\end{array}$ & Infusion or decoction & [6] \\
\hline Northem Mexico & Seeds & $\begin{array}{l}\text { Diuretic, a cure for bronchitis and fever. is effective against parasitic } \\
\text { worms }\end{array}$ & Infusion or decoction & [14] \\
\hline
\end{tabular}

Table 1: Ethnobotanical uses of Cucurbita pepo found world wide.

and spinasterol represented $41.1-53.6 \mathrm{~g} / 100 \mathrm{~g}$ of total sterol content. The third most abundants is the $\Delta^{7}$-stigmasterol, with $12.5-20.3 \mathrm{~g} / 100 \mathrm{and}$ $\Delta^{7.25}$-stigmastadienol, with 5.8-8.0 g/100 g of total sterol content [23].

In seeds, the greatest concentrations of squalene were found with a ranged from 583.2 to $747 \mathrm{mg} / 100 \mathrm{~g}$. Squalene is a triterpene produced by humans, animals and plants, is a precursor of steroid hormones, cholesterol, and vitamins D in their biosynthesis in the human body. Also, squalene is a compound that has positive effects in the treatment of certain types of cancer [23].

In addition, the seeds contain cucurbitosides which are acylated phenolic glycosides as well as cucurbitosides F-M [24].

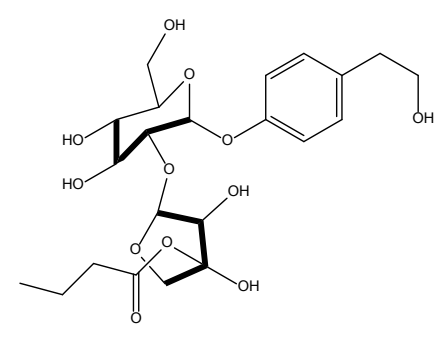

Cucurbitoside F

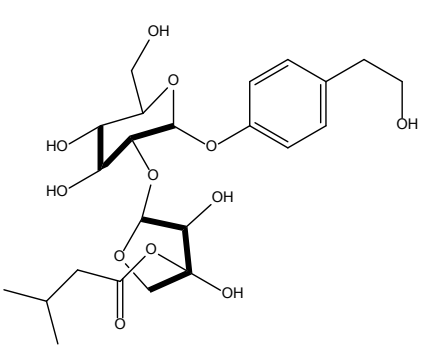

Cucurbitoside G

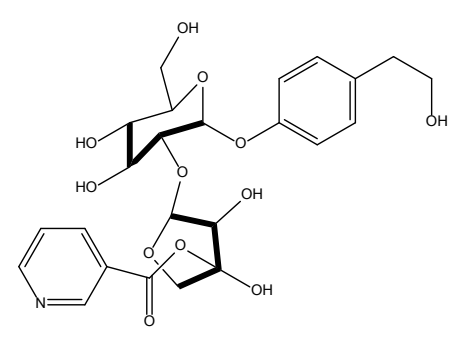

Cucurbitoside $\mathrm{H}$

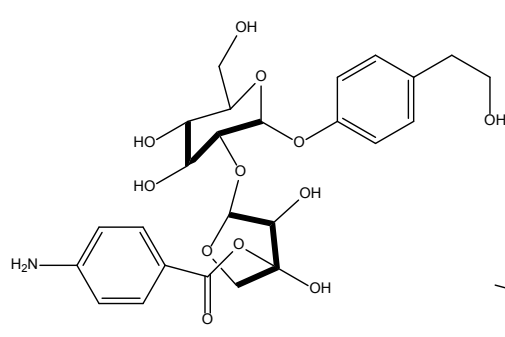

Cucurbitoside I

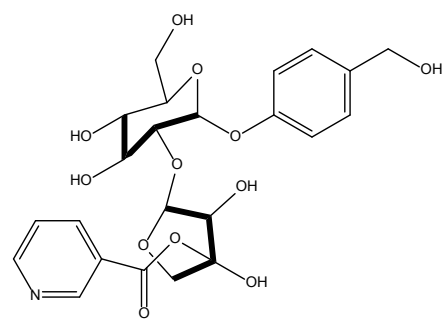

Cucurbitoside L

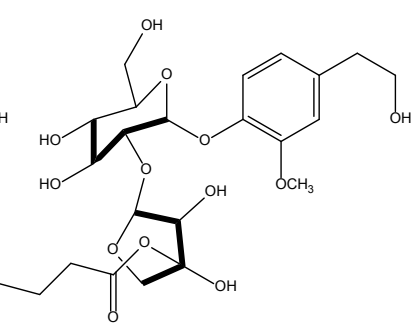

Cucurbitoside J

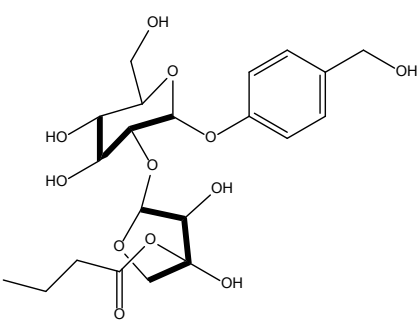

Cucurbitoside K

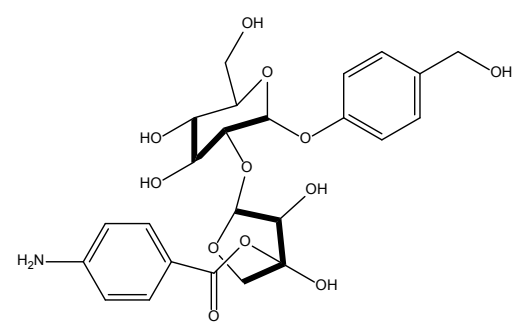

Cucurbitoside $\mathrm{M}$ 
Citation: Perez Gutierrez RM (2016) Review of Cucurbita pepo (Pumpkin) its Phytochemistry and Pharmacology. Med chem 6: $012-021$. doi:10.4172/2161-0444.1000316

Examination of the seeds of C. pepo used HPLC leads to isolation of the following five multiflorane-type triterpenoids [25]. 3a--Nitrobenzoylmultiflora-7:9(11)-diene-29-benzoate 3a-Acetoxymultiflora-7:9(11)-diene-29-benzoate
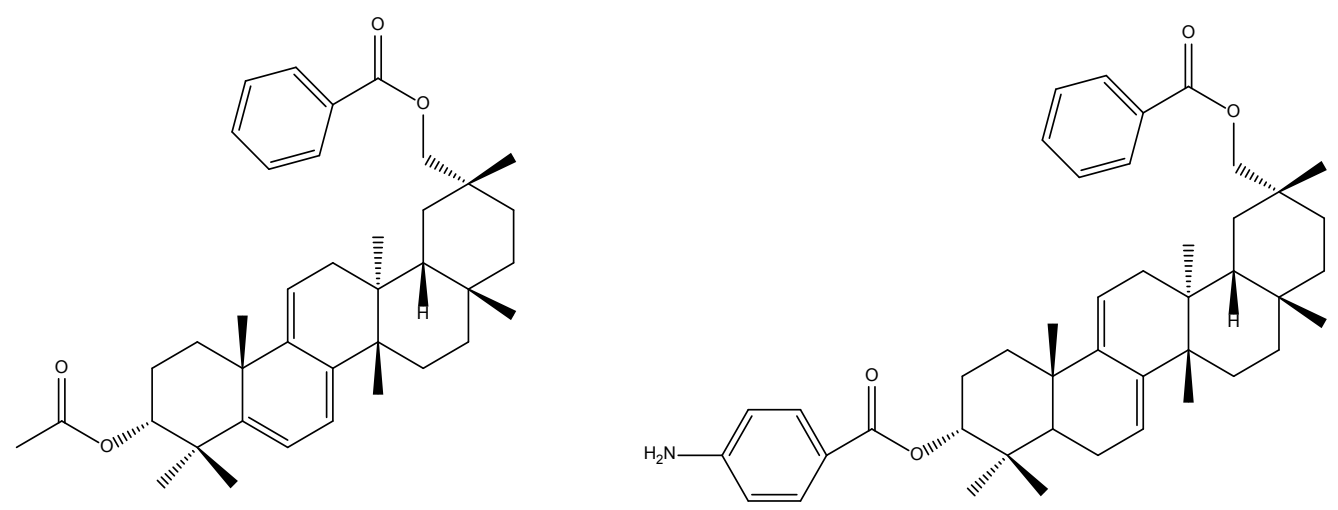

3 $\alpha$-Acetoxymultiflora-5(6):7:9(11)-triene-29-benzoate

3a-p-AminobenzoylmultiJlora-7:9(11)-dien-29-benzoate

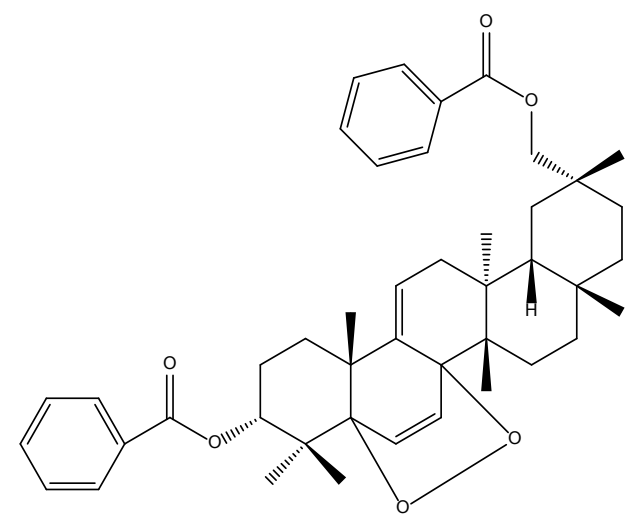

$5 \alpha, 8 \alpha$-Peroxymultiflora-6:9(11)-diene-3 $\alpha, 29$-dibenzoate

In another research thirteen compounds from C. pepo seeds, were isolated [26].

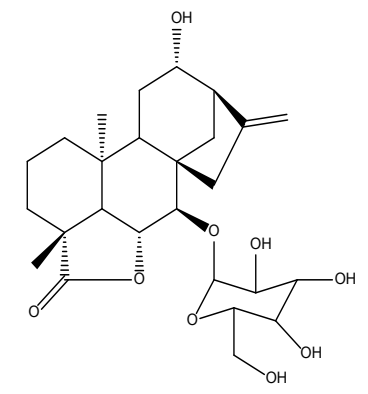

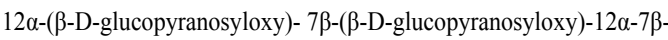
hydroxykaurenolide hydroxykaurenolide

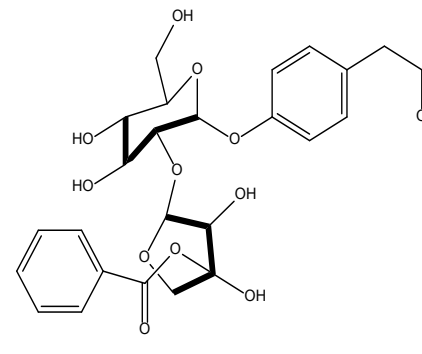

Cucurbitoside A

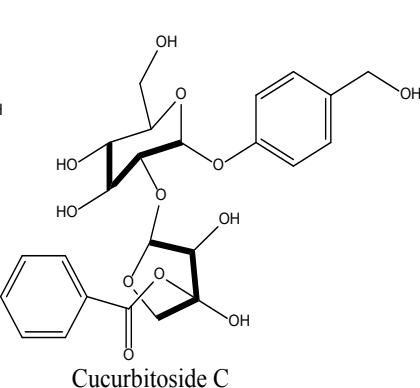

Cucurbitoside C

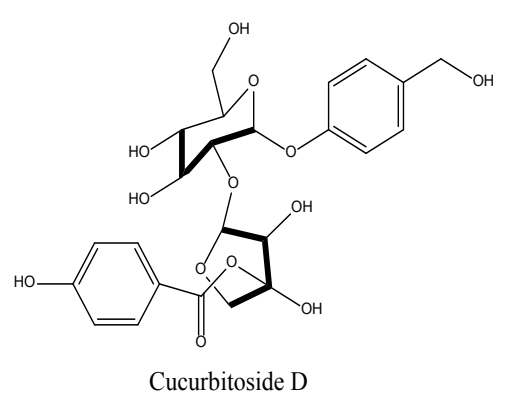


Citation: Perez Gutierrez RM (2016) Review of Cucurbita pepo (Pumpkin) its Phytochemistry and Pharmacology. Med chem 6: $012-021$. doi:10.4172/2161-0444.1000316

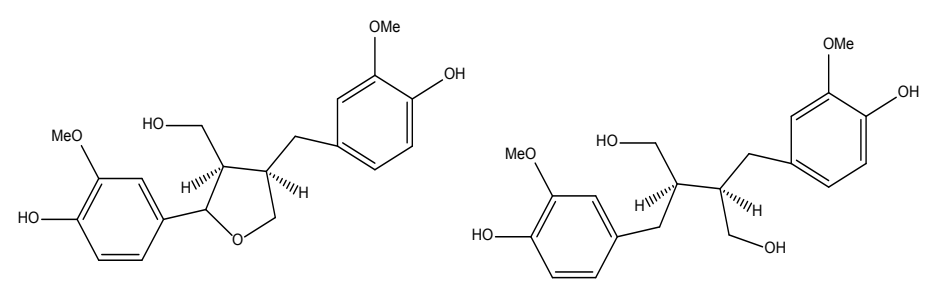

$(+)$-Lariciresinol<smiles>CCC1Cc2cc(O)c(O)cc2[C@H](c2ccc(Cl)c(O)c2)C1CO</smiles>

Isolariciresinol<smiles>COc1cc(C[C@]2(C)COC(c3ccc(OC4OC(CO)C(O)C(O)C4O)c(OC)c3)[C@@]2(C)CO)ccc1O</smiles>

Lariciresinol-4'-O- $\beta$-D-glucoside

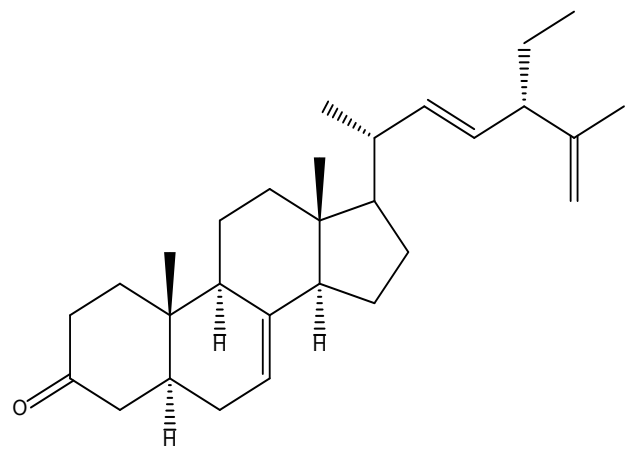

(24S)-stigmasta-7,22E,25-trien-3-one<smiles>COc1cc(C[C@]2(C)COC(c3ccc(O)c(O)c3)[C@@]2(C)CO)ccc1OC1OC(CO)C(O)C(O)C1O</smiles>

Lariciresinol-4-O- $\beta$-D- glucoside<smiles>[2H][C@]12CCC([C@H](C)/C=C/[C@H](CC)C(=C)C)[C@@]1(C)CC[C@@]1(C)C2=CC[C@@H]2C[C@H](O)CC[C@@]21C</smiles>

(24S)-stigmasta-7,22E,25-trien-33-ol

Phytochemical study of the fruits of C. pepo cv dayangua has led to the isolation of two cucurbitane glycosides: cucurbitacin L 2-O-beta-Dglucopyranoside, and cucurbitacin K 2-O-beta-D-glucopyranoside [27].

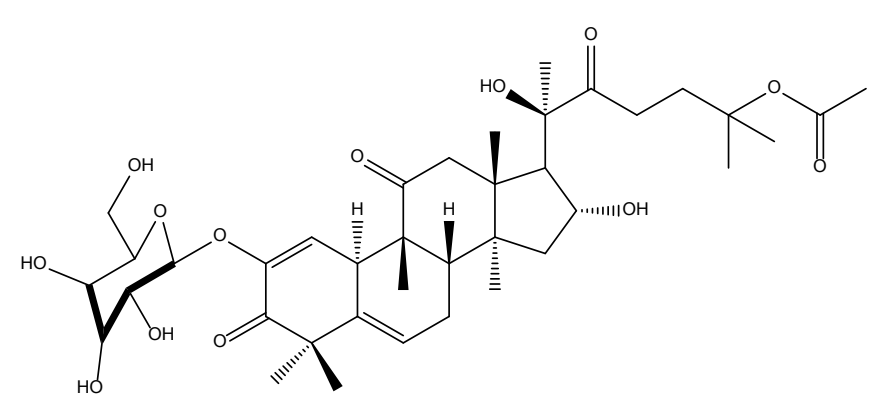

Cucurbitacin L 2-O-beta-D-glucopyranoside

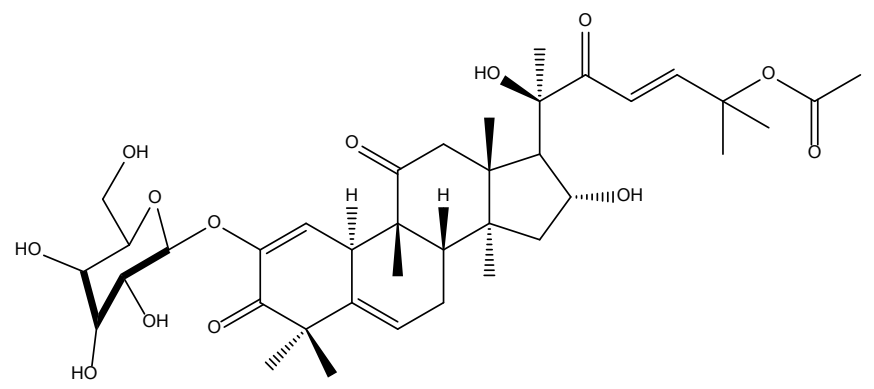

Cucurbitacin k 2-O-beta-D-glucopyranoside 
Citation: Perez Gutierrez RM (2016) Review of Cucurbita pepo (Pumpkin) its Phytochemistry and Pharmacology. Med chem 6: $012-021$. doi:10.4172/2161-0444.1000316

\section{Biological Activity}

Scientific investigations on the medicinal properties of pumpkin dates back to the 1930s. A summary of the findings of these studies performed is presented below.

\section{Antioxidant and free radical scavenger}

Cellular damage or oxidative injury arising from free radicals or reactive oxygen species (ROS) now appears to be the fundamental mechanism underlying a number of human disorders including diabetes, digestive system disorders, viral infections, neurodegenerative disorders, autoimmune pathologies and inflammation. Free radicals are generated through environmental chemicals, xenobiotics, endogenous chemicals, as well as normal metabolism [28].

Tocopherols are non-glycoside are compounds of vegetable oil, and are natural antioxidants. Seeds oil of the pumpkin containing a mixture of isomers $\beta$ and $\delta$-tocopherol in range from 29.92 to $53.60 \mathrm{mg} / 100 \mathrm{~g}$ making $79 \%$ and $84 \%$ respectively of the total tocopherol content [23].

The antioxidant activity of pumpkin seeds methanol extract was determined using free radical DPPH (2,2-diphenyl-1-picrylhydryzyl) scavenging and soybean lipoxygenase [LOX] inhibition. Results expressed as $\mathrm{EC}_{50}$ values for scavenging activity on DPPH radical assay is $5.57 \mathrm{mg} / \mathrm{ml}$. In addition, metanol extract inhibit $50 \%$ of LOX activity at concentrations ranging from $0.3 \mathrm{mg} / \mathrm{ml}$ to $1.02 \mathrm{mg} /$ $\mathrm{ml}$ [29]. This extract contain higher amounts of phenolic compounds (5-11 $\mu \mathrm{mol}$ gallic acid 7-15\% of total extractable phenolics). Radical scavenging effect depend on their total phenolic content. However, the lipoxygenase, inhibition and the phenolic content are not correlated.

In another study of a methanol seeds extract of varietes junona and Miranda both belonging to the species $C$. pepo had to higher total polyphenol content of $82.4 \mathrm{mgGA} / 100 \mathrm{~g}$ and $113 \mathrm{mgGA} / 100 \mathrm{~g}$ respectively [30]. In this study also was measured antioxidant activity from C. pepo by ABTS radical and ferric reducing antioxidant power (FRAO) assays. Results obtained with highest ranges from 0.443 to $1.220 \mu \mathrm{M}$ Trolox/gFW (TEAC) for the hydrophilic form and lowest for lipophilic form of 3.33 to 0.1 TEAC. FRAP assay demonstrate a highest antioxidant effect of $1.83 \mathrm{nmol} / 100 \mathrm{~g} \mathrm{FW}$ [30].

Pumpkin polysaccharides with different degree of substitution were phosphorylated using $\mathrm{POCl}_{3}$ and pyridine. The antioxidant activity of the phosphorylated polysaccharides was determined using free radical $\mathrm{DPPH}$, superoxide anion radical scavenging activity, reducing power and $\mathrm{H}_{2} \mathrm{O}_{2}$-induced oxidative damages on rat thymic lymphocyte. All the phosphorylated polysaccharides derivatives tested showed higher antioxidant activities in both in cell system and in vitro due to highly phosphorylated derivatives have electron donating groups, capable of converting free radicals to stable compounds, indicating that connected moieties between the head and tail portions in electron donating groups have the ability to link using a negative interaction to allosteric sites. Pumpkin polysaccharide exhibiter higher cytoprotective effect than the unmodified polysaccharide in vitro models, indicating that chemical modification could enhance the cytoprotective effect [31].

\section{Hepatoprotective effects}

The hepatoprotective effect of an protein isolated of seeds from C. pepo was studied on Sprague-Dawley rat liver damage induced by acetoaminophen by monitoring serum transaminase including aspartate amino transferase (AST) and serum alanine amino transferase (ALT). The significant increased levels of plasma ALT and AST are the result of acetaminophen intoxication in the liver and kidney injury and leakage of cellular enzymes into the bloodstream as a result of the injury.
The treatment with $C$. pepo seed protein isolate significantly reduced the levels of ALT and AST. In addition, seed protein isolated has good antioxidants effect as revealed by chelating effect, antixanthine oxidase properties, and free radical scavenging activity [32].

In another study, the effect of an protein isolated of seeds from C. pepo on $\mathrm{CCl}_{4}$-induced injury in low-protein fed rats was studied. Administration of this protein caused significant increase en the enzymes antioxidant including catalase (CA), superoxide dismutase (SOD), glutathione peroxidase (GSHpx) as welll as glucose-6phosphatase (G6Pase). However, was significantly decreased the lipid peroxidation (LPO-malondialdehyde-MDA) levels in liver homogenate [33]. Thesel studies have indicated the ability of seeds from C. pepo to reduce several parameters associated with liver injury.

\section{Anti-hyperglycemic}

Diabetes is a metabolic disease which is a serious problem of modern society due to the severe health complications associated with it. Pancreatic $\beta$-cells release insulin which is the hormone responsible for glucose homeostasis [34]. The inappropriate utilization of insulin leads to insulin resistance, which is characterised by the inability of cells to respond to normal levels of circulating insulin, thus leading to glucose metabolism disturbances are main factors leading to diabetes. For this reason therapeutic targets should lead a durable maintenance of glycemic control in the diabetic. Therefore, numerous herbal medicines, found to be effective in the long-term management of type 2 diabetes mellitus.

Tocopherol isomers $(\alpha, \beta, \gamma$, and $\delta$ ) from raw pumpkin seeds has been reported to be effective in the alleviation of diabetes through its antioxidant activities. Tocopherol was extracted and quantified of the seeds oil of $C$. pepo producing $\alpha$ - tocopherol ranged from $75 \mu \mathrm{g} / \mathrm{g}, 75$ $\mu \mathrm{g} / \mathrm{g}$ to $493 \mu \mathrm{g} / \mathrm{g}$ for $\gamma$-tocopherol, and from $35 \mu \mathrm{g} / \mathrm{g}$ to $1110 \mu \mathrm{g} / \mathrm{g}$ for $\delta$-tocopherol. Tocopherol fraction of pumpkin seed oil was studied in hyperglycemia Wistar rats induced with nonionic copolymer PX-407 with impaired response and loss of $\beta$-cell sensitivity to glucose, which is considered as a appropriate model to study the activity of hypoglycemic drug. Results indicated a decreced of insulinemic, lipid profiles and glycemic levels. In addition, in silico constrained an noconstrained docking studies was performed using FRED and HYBRID programs to understand the mechanism of action with respect to three hypoglycemic proteins, PTP1 B, PPAR- $\gamma$, and DPP-IV with respect to 10 botanicals. In nonconstraint docking, all the tocopherols showed interaction in the active sites of the proteins [35]. A significantly reduction in oxidative markers and enhanced cecal and pancreatic characteristics were also observed.

Other Curcurbiteae as Cucurbita ficifolia Bouché (chilacayote) and Cucurbita moshata duch have properties hypoglycemic, increases serum insulin levels; produced a beta cell regeneration [36,37]. It has been shown that the bioactive component in Cucurbita moshata is a polysaccharide [38] though further research has been required to identify if this is true for all members of this family. It has been demonstrated that polysaccharides content in a water extract pumpkin produces higher hypoglycemic effects than those of the glibenclamide (GB) in alloxan-induced diabetic rats [38]. In addition, pumpkin fruit has high concentrations of pectin which is a fibre, when is consumed reduce the need for insulin and control glucose levels [39]. However, the protein-bound polysaccharides from pumpkin reduce the blood glucose levels, and improving the tolerance of glucose [40]. The structural characterization of the purified polysaccharide were evaluated as an acid heteropolysaccharide $(\mathrm{Mw}=27 \mathrm{kDa})$ including Ara, Gal, Glc and GalA in ratio of 2.6:3.6:2:1 with an $\alpha$-configuration. 
It has a backbone composed of $(1 \rightarrow 5)$-linked Ara, $(1 \rightarrow 6)$-linked Gal with three branches attached to O-3 of $(1 \rightarrow 6)$-linked Gal and terminated with either Gal or Gal and Glc, and all of Glc and the majority of GalA are distributed in branches [41]. This polysaccharide $(50 \mathrm{mg} / \mathrm{kg}) \mathrm{administered}$ orally in alloxan-induced diabetic increase the body weight, reduce water intake, and blood glucose levels of diabetic mice group compared with diabetic control group.

In another studies also on alloxan-induced diabetic rats demonstrate that polysaccharide from pumpkins has hypoglycemic effect [42]. Furthermore, the administration of fruit powder for a month in diabetic rats significantly reduced C-reactive protein (CRP), colesterol, glucose, triglycerides while insulin was increased in diabetic rats [43].

Protein-bound polysaccharides (PBPP) are isolated from water extract from pumpkin fruits to consist of $10.13 \%$ protein and $41.21 \%$ polysaccharides. Administration of this protein-bound polysaccharides to alloxan-induced diabetic rat model reduced significantly glucose levels [44]. All these studies indicate that polysaccharides and protein-bound polysaccharides are the bioactives antidiabetic of pumpkin. In clinical study, thirty T2DM diabetic patients were treated with pumpkin polysaccharide granules for four weeks. After treatment there is a reduction in both urination and plasma glucose [45].

Numerous plants are used in South Africa for the treatment of type II diabetes among them they is C. pepo which was evaluated using in vitro $\alpha$-glucosidase and $\alpha$-amylase activity. The results demonstrated inhibitory activity against both enzyme systems adding evidence to the traditional use in the management of the type II diabetic post-prandial hyperglycemia [46].

C. pepo may therefore be beneficial for the prevention of complications related to diabetes, also since its traditional use in diabetes is well established.

\section{Anti ulcer activity}

Cucurbitacin derivative was isolated from metanol extract of powdered seeds of $C$. pepo which showed dose dependent antiulcer activity decreasing ulcerative index indicated the ability of the compound to protect the gastric mucosa [47].

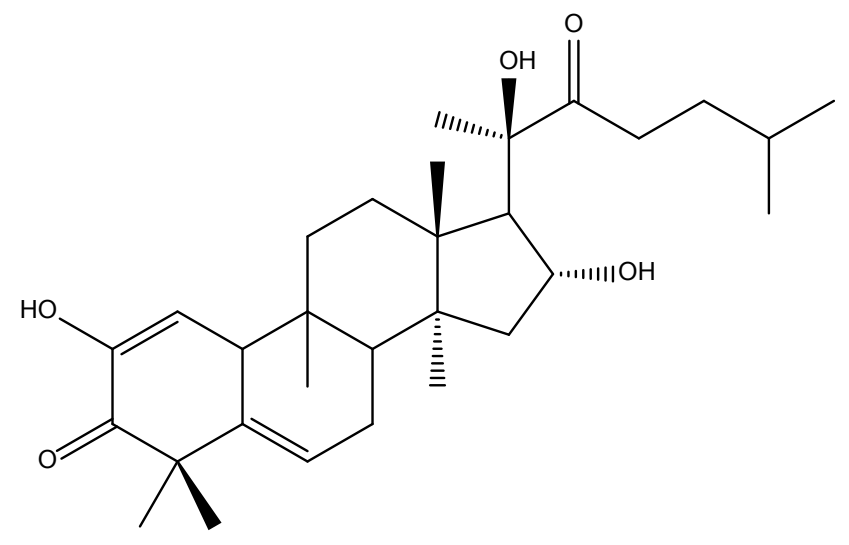

Cucurbitacin derivative

\section{Prostatic hiperplasia (BPH) and urinary function}

Benign prostatic hyperplasia (BPH) result of gradual overgrowth of the prostate gland, which is located at the base of tbe bladder and and surrounds the urethra. The enlarged prostate affects the urethra, and therefore BPH is associated with diminution in urinary function [48]. Management of this disease to include pumpk seeds suggested that the actions of pumpkin seed oil may be attributed to the content of phytosterols, which are known to interfere with the actions of dihydrotestosterone. This is a potent androgen produced in the prostate, from testosterone by the enzyme $5 a$-reductase that lead growth of the prostate. This androgens playing an considerable part in the disease process of BPH, so dihydrotestosterone inhibition reduced growth of the prostate.

In one study, hiperplasia of the rat prostate was induced by a subcutaneous injection of testosterone at a dose of $0.3 \mathrm{mg} / 100 \mathrm{~g}$ daily for $20 \mathrm{days}$. Administration of pumpkin seeds oil ( $14 \mathrm{mg} / \mathrm{kg}$ ) daily for 30 days inhibited testosterone-induced hyperplasia of the rat prostate involving a direct inhibition of growth of the prostate [48].

In a double-blind, placebo controlled study with curbicin isolated from C. pepo seeds in the treatment of patients with symptoms of prostatic hiperplasia over a three month period. The cubicin dose administered to 55 patients was of $160 \mathrm{mg}$ of standardized extract from C. pepo (80 mg). After treatment with cubicin micturition time, frequency of micturition, urinary flow, and residual urine were significantly improvement [49].

In another study forty five patients with urinary dysfunction (overactive bladder, $\mathrm{OAB}$ ) were orally treated with C. máxima seeds oil (10 g/ oil/day) for 12 weeks. Treatment with oil significantly reduced the degree OABSS in patients [50]. OABSS, a self-assessment of OAB symptoms, is recognized as a standard tool for diagnosis and evaluation of the severity of $\mathrm{OAB}$, and has been used in clinical studies [51].

Furthermore, the pumkin seeds oil (10\%) were investigated on citral induced BPH in Wistar rats. Citral significantIy increased prostate weight. However, seeds oil significantIy inhibited enlarged prostate, decrease of protein binding prostate (PBP) levels, weight of ventral prostate size, and amelioration histology of testis. Thus, indicate that seeds oil may be beneficial in the management of mild stage of benign prostatic hiperplasia [52]. 
Citation: Perez Gutierrez RM (2016) Review of Cucurbita pepo (Pumpkin) its Phytochemistry and Pharmacology. Med chem 6: $012-021$. doi:10.4172/2161-0444.1000316

These finding suggested that pumkin seeds oil have the potential to be developed as new chemotherapeutic agents to prevent or to inhibit benign prostatic hiperplasia.

\section{Anti-inflammatory activity}

$3 \beta$-hydroxycholest-7-en-24-one from C. pepo seeds, was isolated and evaluated for macrophage activation by the inhibitory assay of NO production in RAW264.7 mouse macrophages stimulated by LPS. 3 $\beta$-hydroxycholest-7-en-24 one exhibited inhibitory effects on macrophage activation at 3-30 $\mu \mathrm{M}$ (produced NO: $81.3 \%$ at $3 \mu \mathrm{M}, 61.2 \%$ at $10 \mu \mathrm{M}$, and $33.9 \%$ at $30 \mu \mathrm{M}$ ). Triterpene exhibited low cytotoxicity at $30 \mu \mathrm{M}$ (cell viability: $85.9 \%$ at $30 \mu \mathrm{M}$ ), but not at effective concentrations, namely 3 and $10 \mu \mathrm{M}$. These results suggested that isolated steroid has potential as an anti-inflammatory agent [26].

23, 24-dihydrocucurbitacin D [53] blocked NO production from peritoneal macrophages activates with lipopolysaccharides and interferon $\gamma$, with values of $\mathrm{ED}_{50}$ of $13 \mu \mathrm{M}$ and the effect might occur via inhibiting NF-KB activation and iNOs gene transcription. However, did not show cytotoxic to peritoneal macrophages [54].



$3 \beta$-hydroxycholest-7-en-24-one

\section{Antimicrobial activity}

Antimicrobial chemotherapy has revolutionized modern medicine and has significantly reduced death and ailments from infectious diseases. Nevertheless, microorganisms have progressively diminished the effectiveness of previously successful antibiotics by developing resistance. Certain bacterias can secrete an extracelular polymer layer (biofilm) that accumulates and surrounds bacterial cells to resist to antibiotics. Bacteria in a biofilm present more resistance to multiple antibiotics that planktonic bacteria. In intracellular infections most antibiotic have poor cellular penetration and limited intracelular retention. Therefore develop of novel bioactive are of a high interest. The infection caused by multidrug-resistant and pandrug-resistant stains are often hard to treat due therapeutic options. Currently there is a great interest on natural antimicrobial molecules in hope that they may provide useful leads into anti-infective drug candidates.

Extracts of leaves from C. pepo displayed the largest spectra of activity against Providencia stuartii, Pseudomonas aeruginosa, $K$. pneumoniae, Escherichia coli, Enterobacter aerogenes and Enterobacter cloacae. The extract from C. pepo was more active than chloramphenicol used as positive control on at least one of the tested MDR bacteria. The activity of chloramphenicol increased in the presence of $P A \beta N$ in the majority of the tested bacteria. The extract from C. pepo leaves showed the best MBC spectrum with the values below to $1024 \mu \mathrm{g} / \mathrm{ml}$ recorded on $58.62 \%(17 / 29)$ of the studied microorganisms [55].

In another research, the methanolic extract of fruit of C. pepo were evaluated for antimicrobial activity against bacterial strains Bacillus cereus, Bacillus subtilis, Escherichia coli, Enterobacter aerogenes, Enterobacter agglomerans, Salmonella enteritidis, SalmoneIla cholerasius, Staphylococcus aureus, Pseudomonas aeruginosa, Candida albicans, Penicillium chrysogenum, Enterobacter faecalis, Klebsiella pneumonia, Bisphericus, B. thruengenesis and Cryptococcus meningitis. The extract showed moderate to high activity against all the investigated microbial strains [56].

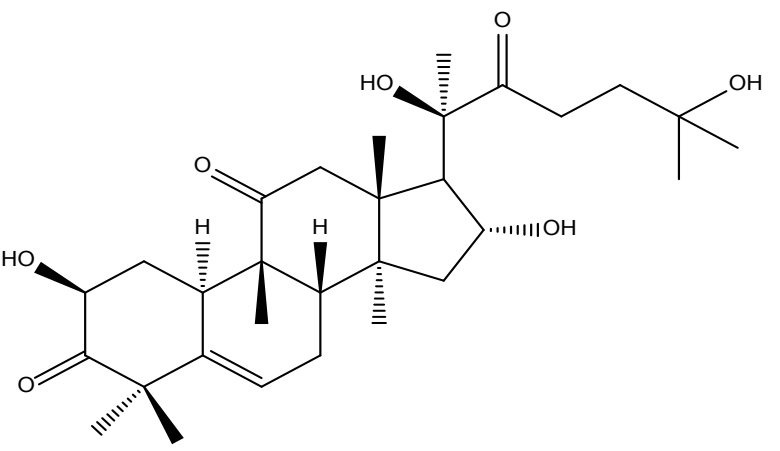

23, 24-dihydrocucurbitacin D

\section{Anticancer/antitumour effects}

Cancer is one of the main health problems of all the world. Cancer is responsible for $12 \%$ of the world's mortality. Treatments include chemotherapy surgery, and radio-theraphy. However, chemotherapy suffers limitations of drug resistance, toxicity, side-effects and lacking specificity toward tumor cells [57]. Therefore, there is a strong interest in the use of plants as a promising source of more efficient anticancer drugs.

Currently more than 40 cucurbitacin-derived compounds and cucurbitacins and have been isolated from the Cucurbitaceae family and from other species of the plant. The apoptotic effects of cucurbitacins is due of their ability to modify the genes, transcriptional activities via nuclear factors and mitochondrial trans-membrane potential and their capability to activate or inhibit pro- or anti-apoptotic proteins. Cucurbitacins are selective inhibitors of the JAK/STAT pathways; also, other mechanisms are implicated in their apoptotic effects, such as PARP cleavage, MAPK pathway, expression of active caspase- 3 , decreased JAK3 and pSTAT3 levels, as well as decreases in various downstream STAT3 targets such as Bcl-2, Mcl-1, cyclin D3, and Bcl$\mathrm{xL}$, all of which are implicated in the cell cycle control [58].

Alcoholic extract of Cucurbita pepo showed $\mathrm{IC}_{50}$ values on cancer cell lines HepG2 and CT26 of 132.6 and $167.2 \mu \mathrm{g} / \mathrm{ml}$ respectively. The ethanolic extract of fruits of $C$. pepo was observed to exhibit a significant dose-dependent inhibitory effect against HeLa cell growth [59].

Cucurbitacins have been reported mainly in the Cucurbutacea, are a class of highly oxidized tetracyclic triterpenoids possess the biogenetically unusual 10 $\alpha$-cucurbit-5-ene[19(10 $\rightarrow 19 \beta)$ abeo-10 $\alpha$ lanostane skeleton which are well known for their cytotoxic activity. The ethanolic extract of air-dried fruits of C. pepo was subjected to chromatography to give cucurbitaglycosides A and B. In vitro assay both compounds showed weak cytotoxic activity against HeLa cells with $\mathrm{IC}_{50}$ values of 17.2 and $28.5 \mu \mathrm{g} / \mathrm{ml}$ respectively [60]. 


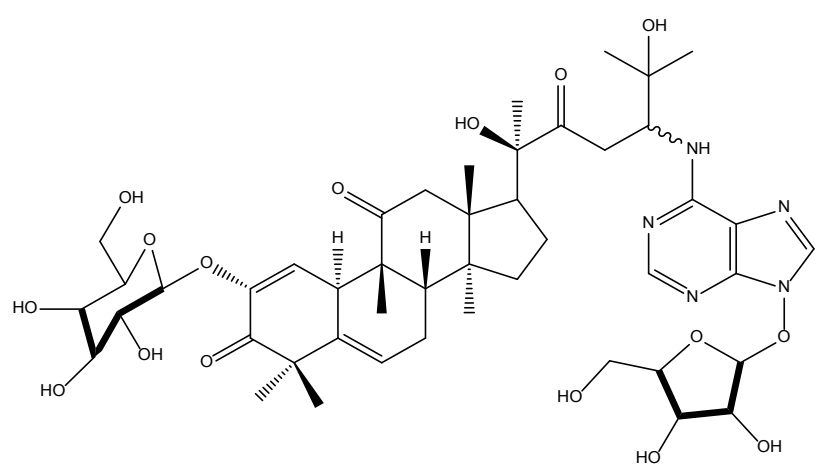

Cucurbitaglycosides A

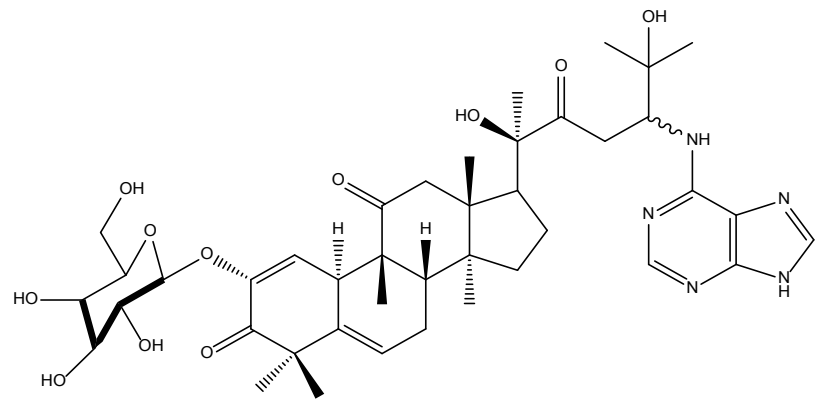

Cucurbitaglycosides B

Feng et al. [53] found that C. pepo cv dayangua contain 23, 24-dihydrocucurbitacin F, 23, 24-dihydrocucurbitacin D, cucurbitacin B and cucurbitacin E.

The antiproliferative effect of 23, 24-dihydrocucurbitacin F, on human PCa cells might occur to the induction of the cofilin-actin rod formation and actin aggregation producing to cell cytokinesis failure, inhibited cell growth cycle arrest at G2/M phase and apoptosis [61]. In addition, 23,24-dihydrocucurbitacin $\mathrm{F}$ have been inhibitory activity on Epstein-Barr virus (EBV) activation induced by the tumor promoter, 12-O-tetradecanoyl-phorbol-13-acetate (TPA) and also exhibit significantly anti-tumor-promotion activity on mouse skin tumor promotion [62].

Cucurbitacin B and cucurbitacin E characterized from C. pepo cv dayangua has been shown antiproliferative in breast (MCF-7), colon (HCT116), brain (SF-268), lung cancer cells (A549) and lung (NCI-H460) cancer cell lines, among them cucurbitacin B demonstrated more than 80\% proliferation inhibitory activity [63].

Treatment with cucurbitacins B and E showed growth inhibition accompanied by apoptosis and cell cycle arrest in breast cancer cell lines (MDAMB-231 and MCF-7) [64]. They also modulated the expression of proteins involved in cell-cycle regulation in both of the estrogen-independent (MDA- MB-231) and estrogen-dependent (MCF-7) in human breast cancer cell lines [65]. Growth inhibition and cytotoxic effect of cucurbitacin B on breast cancer cell lines SKBR-3 and MCF-7 were attributed to G2/M phase arrest and apoptosis. Cucurbitacin B treatment inhibited Cyclin $\mathrm{D} 1, \mathrm{c}-\mathrm{Myc}$, and $\beta$-catenin expression levels, translocation to the nucleus of $\beta$-catenin and galectin-3. Western blot analysis showed increased PARP cleavage suggesting induced caspase activity and decreased mitogenic Wnt-associated signaling molecules galectin-3, $\beta$-catenin, c-Myc, and cyclin D1 with changes in phosphorylated GSK-3 $\beta$ levels [66].

Cucurbitacin E caused disruption of the cytoskeleton structure of actin and vimentin inhibing the proliferation of prostate cancer cells [67]. Moreover, cucurbitacins also inhibited proliferation of endothelial cells accompanied by a disruption of the F-actin and tubulin microfilaments cytoskeleton, normal mitogen-induced T-lymphocytes [68] and reduced cell motility suggest an anti-angiogenesis and anti-metastasis role for cucurbitacins [67]. In addition is capable of inducing and maintaining high proliferation rates in lymphocytes [69].<smiles>CC(C)(O)CCC(=O)C(C)(O)C1[C@@H](O)C[C]2C3CC=C4[C@@H](C[C@H](O)[C@H](O)C4(C)C)C3CC[C@@]21C</smiles>

23, 24-dihydrocucurbitacin F<smiles></smiles>

Cucurbitacin B

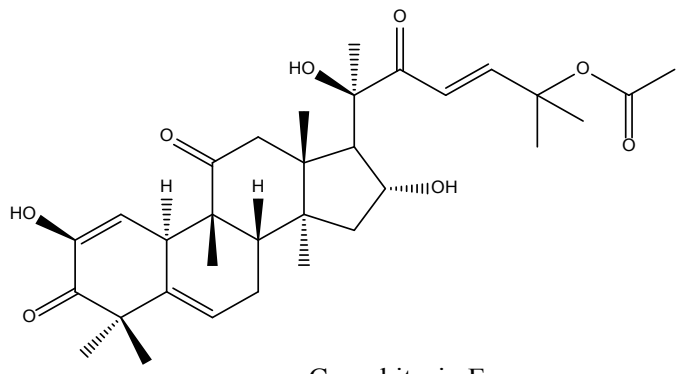

Cucurbitacin E 
Citation: Perez Gutierrez RM (2016) Review of Cucurbita pepo (Pumpkin) its Phytochemistry and Pharmacology. Med chem 6: $012-021$. doi:10.4172/2161-0444.1000316

These finding suggested that C. pepo extracts have the potential to be developed as new chemotherapeutic agents to prevent or to inhibit the growth of tumours and cancers.

\section{References}

1. Smith BD (1997) The initial domestication of Cucurbita pepo in the Americas 10,000 years ago. Sci 276: 932-934.

2. Wang XL, Liu J, Chen ZHB, Gao F, Liu JX, Wang XL (2001) Preliminary study on pharmacologically effect of Curcurbita pepo cv Dayanggua. J Trad Chin Vet Med 20: 6-9.

3. Ding YL, Deng XM, Wang XL, Wang IQ, Zhang YP (2002) Study on Newcastle disease virus effect of five traditional Chinese herbs. J Trad Chin Vet Med 21: 3-4.

4. Chaturvedi $P$ (2012) Antidiabetic potentials of Momordica charantia: multiple mechanisms behind the effects. J Med Food 15: 101-107.

5. Caili F, Huan S, Quanhong L (2006) A review on pharmacological activities and utilization technologies of pumpkin. Plant Foods Hum Nutr 61: 73-80.

6. Dhiman K, Gupta A, Sharma DK, Gill NS, Goyal A (2012) A review on the medicinally important plants of the family Cucurbitaceae. Asian J Clin Nutr 4: 16-26.

7. Yang BM, Yang ST, Chen SN (2000) A preliminary study on the cultivating technique of Cucurbita pepo cv Dayangua. Spec Econ Amin Plant 3: 28-34.

8. Kessler OJ, Keisari Y, Servadio C, Abramovici A (1998) Role of chronic inflammation in the promotion of prostatic hyperplasia in rats. J Urol 159: 10491053.

9. Madaus G (1979) Lehrbuch der biologischen heilmitted. Band III. Hildesheim. Georg Olms Verlag. pp: 2384-2387.

10. State Administration of Traditional Chine Medicine (1999) Zhong-hua-ben-cao: Shanghai Science Technology Press, Shanghai. p: 4600.

11. Bombardelli E, Morazoni P (1997) Pumpkin seed inhibitor of human factor Xlla (activared Hageman factor) and bovine trypsin. Fitorerapia 68: 291-302.

12. Jiang Z, Du Q (2011) Glucose-lowering activity of novel tetrasaccharide glyceroglycolipids from the fruits of Cucurbita moschata. Bioorganic Med Chem Lettrs 21: 1001-1003.

13. Dabaghian FH, Kamalinejad M, Shojaei Am FMA (2012) Presenting antidiabetic plants in Iranian traditional medicine. J Diabetes Endocrinol 3: 70- 76.

14. McGinley M (2011) Cucurbita pepo. The encyclopedia of earth. Edible medicinal and non-medicinal plants. Volume 2. Fruits. Springer Netherlands.

15. Adedayo OR, Farombi AG, Oyekanmi AM (2013) Proximate, mineral and antinutrient evaluation of pumpkin (Cucurbita pepo). J Applied Chem 4: 25-28.

16. Carvalho LMJ, Smiderle LAZM, Carvalho JLV, Cardoso FSN, Koblitz MGB (2014) Assessment of carotenoids in pumpkins after different home cooking conditions. Food Sci Technol 34: Campinas April/June.

17. [No authors listed] (1993) Evaluation of certain food additives and contaminants Forty-first report of the Joint FAO/WHO Expert Committee on Food Additives. World Health Organ Tech Rep Ser 837: 1-53.

18. Phillips KM, Ruggio DM, Ashraf-Khorassani M (2005) Phytosterol composition of nuts and seeds commonly consumed in the United States. J Agric Food Chem 53: 9436-9445.

19. Sabudak T (2007) Fatty acid composition of seed and leaf oils of pumpkin Walnut almond, maize, sunflower and melon. Chem Nat Compounds 43: 465467.

20. Stevenson DG, Eller FJ, Wang L, Jane JL, Wang T, et al. (2007) Oil and tocopherol content and composition of pumpkin seed oil in 12 cultivars. J Agric Food Chem 55: 4005-4013.

21. Glew RH, Glew RS, Chuang LT, Huang YS, Millson M, et al. (2006) Amino acid mineral and fatty acid content of pumpkin seeds (Cucurbita spp) and Cyperu: esculentlls nuts in the Republic of Niger. Plant Foods Hum Nut 61: 51-56.

22. Rabrenovic CC, Dimic EB, Novakovic MM, Tesevic VV, Basic ZN (2014) The most important bioactive components of cold pressed oil from different pumpkin (Cucurbita pipo L.) seeds. Food Sci Technol 55: 521-527.

23. Matus Z, Molnar P, Szabo LG (1993) Main carotenoids in pressed seeds (Cucurbitae semen) of oil pumpkin (Cucurbita pepo convar. pepo var. styriaca). Acta Pharm Hung 63: 247-256.
24. Li W, Koike K, Tatsuzaki M, Koide A, Nikaido T (2005) Cucurbitosides F-M acylated phenolic glycosides from the seeds of Cucurbita pepo. J Nat Prod 68 : 1754-1757.

25. Tanaka R, Kikuchi T, Nakasuji S, Ue Y, Shuto D, et al. (2013) A novel 3a-pNitrobenzoylmultiflora-7:9(11)-diene-29-benzoate and two new triterpenoids from the seeds of zucchini (Cucurbita pepo L). Molecules 18: 7448-7459.

26. Kikuchi T, Ando H, Maekawa K, Arie H, Yamada T, et al. (2015) Two new entkaurane-type diterpene glycosides from zucchini (Cucurbita pepo L.) seeds. Fitoterapia 107: 69-76.

27. Wang DC, Pan HY, Deng XM, Xiang H, Gao HY, et al. (2007) Cucurbitane and hexanorcucurbitane glycosides from the fruits of Cucurbita pepo $\mathrm{cv}$ dayangua. J Asian Nat Prod Res 9: 525-529.

28. Masuda T, Inaba Y, Maekawa T, Takeda Y, Yamaguchi H, et al. (2003) Simple detection method of powerful antirradical compounds in the raw extract of plants and its appli- cation for the identification of antiradical plants constituents. $J$ Agriculture Food Chem 51: 1831-1838.

29. Xanthopoulou MN, Nomikos T, Fragopoulou E, Antonopoulou S (2009) Antioxidant and lipoxygenase inhibitory activities of pumpkin seed extracts. Food Res Intern 142: 641-646.

30. Nawirska-Olszanska A, Kita A, Biesiada A, Sokol Letowska A, Kucharska AZ (2013) Characteristics of antioxidant activity and composition of pumpkin seed oils in 12 cultivars. Food Chem 139: 155-161.

31. Song $\mathrm{Y}, \mathrm{Ni} Y, \mathrm{Hu} X, \mathrm{Li} \mathrm{Q}$ (2015) Effect of phosphorylation on antioxidant activities of pumpkin (Cucurbita pepo, Lady godiva) polysaccharide. Int J Bio Macromol 81: 41-48

32. Nkosi CZ, Opoku AR, Terblanche SE (2006) In Vitro antioxidative activity of pumpkin seed (Cucurbita pepo) protein isolate and its in vivo effect on alanine transaminase and aspartate transaminase in acetaminophen- induced liver injury in low protein fed rats. Phytother Res 20: 935-940.

33. Nkosi CZ, Opoku AR, Terblallche SE (2006) Antioxidative effects of pumpkin seed (Cucurbita pepo) protein isolate in cci4-induced liver injury in low- protein fed Rats. Phytother Res 20: 935-940.

34. Sesti G (2006) Pathophysiology of insulin resistance. Best Pract Res Clin Endocrinol Metab 20: 665-679.

35. Bharti SK, Kumar A, Sharma NK, Prakash BO, Jaiswal SK, et al. (2013) Tocopherol from seeds of Cucurbita pepo against diabetes: Validation by in vivo experiments supported by computational docking. J Formosan Med Assoc 112: $676-690$.

36. Alarcon-Aguilar FJ, Hernandez-Galicia E, Campos-Sepulveda AE, XolalpaMolina S, Rivas-Vilchis JF, et al. (2002) Evaluation of the hypoglycemic effect of Cucurbita ficifolia Bouche (Cucurbitaceae) in different experimental models. $\mathrm{J}$ Ethnopharmacol 82: 185-189.

37. Zhang Y, Chen P, Zhang Y, Jin H, Zhu L, et al. (2013) Effects of polysaccharide from pumpkin on biochemical indicator and pancreatic tissue of the diabetic rabbits. Int J Biol Macromol 62: 574-581.

38. Zhang YJ (2004) Study on the hypoglycemic effects and extraction and analysis of pumpkin polysaccharide. J China Jiliang University 15: 0238-0241.

39. Guillon F, Champ M (2000) Structural and physical properties of dietary fibres and consequences of processing on human physiology. Food Research International 33: 233-245.

40. Quanhong L, Caili F, Yukui R, Guanghui H, Tongyi C (2005) Effects of proteinbound polysaccharide isolated from pumpkin on insulin in diabetic rats. Plan Foods Hum Nutr 60: 13-16.

41. Tong H, Liang Z, Wang G (2008) Structural characterization and hypoglycaemic activity of a polysaccharide isolated from the fruit of Physalis alkekengi $\mathrm{L}$. Carbohydrate Polym 71: 316-323.

42. Xiong X, Cao J (2001) Study of extraction and isolation of effective pumpkin polysaccharide component and its reducing glycemia function. Chinese $J$ Modern Application Pharm 18: 662-664

43. Sedigheh A, Jamal MS, Mahbubeh S, Sornayeh K, Mahmoud R, et al. (2011 Hypoglycaemic and hypolipidemic effects of pumpkin (Cucurbita pepo L.) on alloxan-induced diabetic rats. Afr J Pharm Pharmacol 5: 2620-2626.

44. Shan J, Ren F, Tian G (2009) Structure characterization and hypoglycemic activity of a glococonjugate from atractylodes macrocephalae koidz. Functiona Plant Sci Biotechnol 3: 36-41.

45. Shi $Y$, Xiong X, Cao J, Kang M (2003) Effect of pumpkin polysaccharide 
Citation: Perez Gutierrez RM (2016) Review of Cucurbita pepo (Pumpkin) its Phytochemistry and Pharmacology. Med chem 6: $012-021$. doi:10.4172/2161-0444.1000316

granules on glycemic control in type 2 diabetes. Central South Pharm 1: 275276.

46. Boaduo NK, Katerere D, Eloff JN, Naidoo V (2014) Evaluation of six plant species used traditionally in the treatment and control of diabetes mellitus in South Africa using in vitro methods. Pharm Biol 52: 756-761.

47. Gill NS, Bali M (2011) Type triterpenoid from the seeds of Cucurbita pepo. Res J Phytochemistry 5: 70-79.

48. Gossell-Williams M, Davis A, O'Connor N (2006) Inhibition of testosteroneinduced hyperplasia of the prostate of sprague-dawley rats by pumpkin seed oil. J Med Food 9: 284-286.

49. Carbin BE, Larsson B, Lindahl O (1990) Treatment of benign prostatic hyperplasia with phytosterols. Br J Urol 66: 639-641.

50. Nishimura M, Ohkawara T, Sato H, Takeda H, Nishihira J (2014) Pumpkin Seed Oil Extracted From Cucurbita maxima Improves Urinary Disorder in Human Overactive Bladder. J Tradit Complement Med 4: 72-74.

51. Homma Y, Yoshida M, Seki N, Yokoyama O, Kakizaki H, et al. (2006) Symptom assessment tool for overactive bladder syndrome--overactive bladder symptom score. Urology 68: 318-323

52. Abdel-Rahman MK (2006) Effect of pumpkin seed (Cucurbita pepo L.) diets of benig prostatic hyperplasia (bph): chemical and morpbometric evaluation in rats. World J Chem 1: 33-40.

53. Feng XS, Wang DC, Cai H, Deng XM, Liu YR (2007) Determination of the cucurbitacins from Cucubita pepo cv dayangua by HPLC. Zhong Yao Cai 30: 418-420.

54. Park CS, Lim H, Han KJ, Baek SH, Sohn HO, et al. (2004) Inhibition of nitric oxide generation by 23,24 -dihydrocucurbitacin $D$ in mouse peritoneal macrophages. J Pharmacol Exp Ther 309: 705-710.

55. Noumedem JAK, Mihasan M, Lacmata ST, Stefan M, Kuiate JR, et al. (2013) Antibacterial activities of the methanol extracts of ten Cameroonian vegetables against Gram-negative multidrug-resistant bacteria. BMC Complement Altern Med 13: 26-29.

56. Dubey A, Mishra N, Singh N (2010) Antimicrobial activity of some selected vegetables. IJABTP 1: 995-999.

57. Chen X, Bao J, Guo J, Ding Q, Lu J, et al. (2012) Biological activities and potential molecular targets of cucurbitacins: a focus on cancer. Anticancer Drugs 23: 777-787.
58. Rios JL, Andujar I, Escandell JM, Giner RM, Recio MC (2012) Cucurbitacins as inducers of cell death and a rich source of potential anticancer compounds. Curr Pharm Des 18: 1663-1676.

59. Shokrzadeh M, Azadbakht M, Ahangar N, Hashemi A, Saeedi SSS (2010) Cytotoxicity of hydro-alcoholic extracts of Cucurbitapepo and Solanum nigrum on HepG2 and CT26 cancer cell lines. Pharmacogn Mag 6: 176-179.

60. Wang DC, Xiang H, Li D, Gao HY, Cai H, et al. (2008) Purine- containing cucurbitane triterpenoids from Cucurbita pepo cv dayangua. Phytochernistry 69: $1434-1438$.

61. Ren S, Ouyang DY, Saltis M, Xu LH, Zha QB, et al. (2012) Anti-proliferative effect of 23, 24-dihydrocucurbitacin $F$ on human prostate cancer cells through induction of actin aggregation and cofilin-actin rod formation. Cancer Chemother Pharmacol 70: 415-424.

62. Konoshima T, Takasaki M, Tatsumoto T, Kozuka M, Kasai R, et al. (1994) Inhibitory effects of cucurbitane triterpenoids on Epstein-Barr virus activation and two-stage carcinogenesis of skin tumors. Biol Pharm Bull 17: 668-671.

63. Jayaprakasam B, Seeram NP, Nair MG (2003) Anticancer and antiinflammatory activities of cucurbitacins from Cucurbita andreana. Cancer Lett 189: 11-16.

64. Sun J, Blaskovich MA, Jove R, Livingston SK, Coppola D, et al. (2005) Cucurbitacin Q: a selective STAT3 activation inhibitor with potent antitumor activity. Oncogene 24: 3236-3245.

65. Blaskovich MA, Sun J, Cantor A, Turkson J, Jove R, et al. (2003) Discovery of JSI-124 (cucurbitacin I), a selective Janus kinase/signal transducer and activator of transcription 3 signaling pathway inhibitor with potent antitumor activity against human and murine cancer cells in mice. Cancer Res 63: 12701279.

66. Dakeng S, Duangmano S, Jiratchariyakul W, Pratya YU, Bogler O, et al. (2012) Inhibition of Wnt signaling by cucurbitacin B in breast cancer cells: reduction of Wnt- associated proteins and reduced translocation of galectin-3-mediated ß- catenin to the nucleus. J Cell Biochem 113: 49-60.

67. Duncan MD, Duncan KL (1997) Cucurbitacin E targets proliferating endothelia J Surg Res 69: 55-60.

68. Smit HF, van den Berg AJ, Kroes BH, Beukelman CJ, Quarles van Ufford $\mathrm{HC}$, et al. (2000) Inhibition of T-lymphocyte proliferation by cucurbitacins from Picrorhiza scrophulariaeflora. J Nat Prod 63: 1300-1302.

69. Attard E, Cuschieri A Scicluna-Spiteri A, Brincat MP (2004) The effects of cucurbitacin E on two lymphocyte models. Pharm Biol 42: 170-175. 